\title{
Modelling and Predicting the Breaking Strength and Mass Irregularity of Cotton Rotor-Spun Yarns Containing Cotton Fiber Recovered from Ginning Process by Using Artificial Neural Network Algorithm
}

\author{
Mohsen Shanbeh, Hossein Hasani, and Somayeh Akhavan Tabatabaei \\ Textile Engineering Department, Isfahan University of Technology, Isfahan 84156-83111, Iran \\ Correspondence should be addressed to Mohsen Shanbeh, mshanbeh@cc.iut.ac.ir
}

Received 9 March 2011; Accepted 13 April 2011

Academic Editor: Philippe Boisse

Copyright (C) 2011 Mohsen Shanbeh et al. This is an open access article distributed under the Creative Commons Attribution License, which permits unrestricted use, distribution, and reproduction in any medium, provided the original work is properly cited.

\begin{abstract}
One of the main methods to reduce the production costs is waste recycling which is the most important challenge for the future. Cotton wastes collected from ginning process have desirable properties which could be used during spinning process. The purpose of this study was to develop predictive models of breaking strength and mass irregularity $\left(\mathrm{CV}_{m} \%\right)$ of cotton waste rotor-spun yarns containing cotton waste collected from ginning process by using the artificial neural network trained with backpropagation algorithm. Artificial neural network models have been developed based on rotor diameter, rotor speed, navel type, opener roller speed, ginning waste proportion and yarn linear density as input parameters. The parameters of artificial neural network model, namely, learning, and momentum rate, number of hidden layers and number of hidden processing elements (neurons) were optimized to get the best predictive models. The findings showed that the breaking strength and mass irregularity of rotor spun yarns could be predicted satisfactorily by artificial neural network. The maximum error in predicting the breaking strength and mass irregularity of testing data was $8.34 \%$ and $6.65 \%$, respectively.
\end{abstract}

\section{Introduction}

Waste recycling is the most important challenge for the future. For minimizing the production costs, exploitation of raw material should be improved. Two solutions for this problem have been proposed. First, providing a highcleaning efficiency during the blowing and carding processes and second, recovery of fibers from wastes [1].

The emerging rotor and friction spinning technology has been marketed on the premise of being able to spin lower grade cotton into acceptable yarn quality at considerable savings [2]. Many researchers [1, 3, 4] have discussed the reuse of recovered fibers in spinning process. It is reported that waste fibers can be blended with primary raw material with a percentage up to $20 \%$, without noticeable changes in quality [1]. All those studies have discussed the effect of the fibers recovered from blowing and carding processes on the yarn quality. Using fibers collected from ginning process is naturally more economical than the fibers recovered from blowing and carding processes.

Artificial neural networks (ANNs) or connectionist models, parallel distributed processing models, and neuromorphic systems represent a set of very powerful mathematical techniques for modeling, control and optimization. An artificial neural network is an information-processing system that has certain performance characteristics in common with biological neural networks. This technique is useful when there are large number of effective factors on the specific process. ANN models are called as "black box" as they simply connect the inputs and outputs without understanding any physical information about the process $[5,6]$.

In recent years, ANN models have been widely used to predict the yarn properties produced in different spinning systems such as air-jet, rotor and ring spinning. Beltran et al. 
[7] proposed ANN model to predict the worsted spinning process. Tensile properties of air-jet spun yarns based on nozzle parameters, namely, nozzle pressure and nozzle design were studied by Zeng et al. [8]. Breaking elongation of ring spun cotton yarns were predicted using mathematical, statistical, and ANN models by P. K. Majumdar and A. Majumdar [9]. Fiber elongation and uniformity index were reported as dominant parameters on breaking elongation in this research. Tensile properties of air-jet spun yarns was predicted by Ramsh et al. [10]. Performance of artificial neural network model, neuro-fuzzy algorithm, and linear regression to predict the breaking elongation of rotor-spun yarns was studied by Majumdar et al. [11]. Cheng and Adams [12] investigated neural networks as yarn strength predictors based on fiber properties measured by HVI testing system. Zhu and Ethridge [13] tried to predict the ring and rotor yarn hairiness from fiber properties measured by three different systems, that is, HVI, AFIS, and the traditional instruments. The fiber length also showed the main effect on yarn hairiness. Sette et al. [14] used a neural network to model the spinning process with 41 fiber properties and 5 machine parameters as input and 9 yarn properties as output. The breaking elongation of polyester/viscose rotor-spun yarns was also predicted by backpropagation multi layer perceptron algorithm [15]. Tensile properties, that is, breaking strength and breaking elongation of cotton-covered nylon core-spun yarns was predicted by Gharehaghaji et al. [16].

Breaking strength and mass irregularity have been known as two main parameters which effect the performance of spun yarns during downstream processes and also quality of fabrics. In this paper, two artificial neural network models have been developed for prediction of breaking strength and mass irregularity $\left(\mathrm{CV}_{m} \%\right)$ of rotor-spun yarns produced from different ratios of cotton fibers and fibers recovered from ginning process. Process parameters of rotor spinning, namely, rotor diameter, navel type, rotor speed, opener roller speed, yarn count, and finally cotton ginning waste percentage were used as input parameters of predictive models. On the other hand, impact of input parameters was evaluated in accordance with obtained ANN models.

A neural network consists of a large number of simple processing elements called neurons, units, cells, nodes, or processing elements. Each neuron receives connections from other neurons and/or itself, each with an associated weight. The interconnectivity defines the topology of the ANN. The weights represent information being used by the neural network model to solve a problem. One of the central issues in neural network design is to utilize systematic procedures (a training algorithm) to modify the weights directly from the training data without any assumptions about the data's statistical distribution $[5,17]$. There are different kinds of topologies and training algorithms, but the feedforward neural network with backpropagation learning algorithm is more popular. In this structure, the neurons are located in layers and from one layer to another one connected with each other with links to carry the signals between them. There is a weight for each connection link which acts as a multiplication factor to the transmitted signal. An activation function such as linear, sigmoid, or others. is applied to each

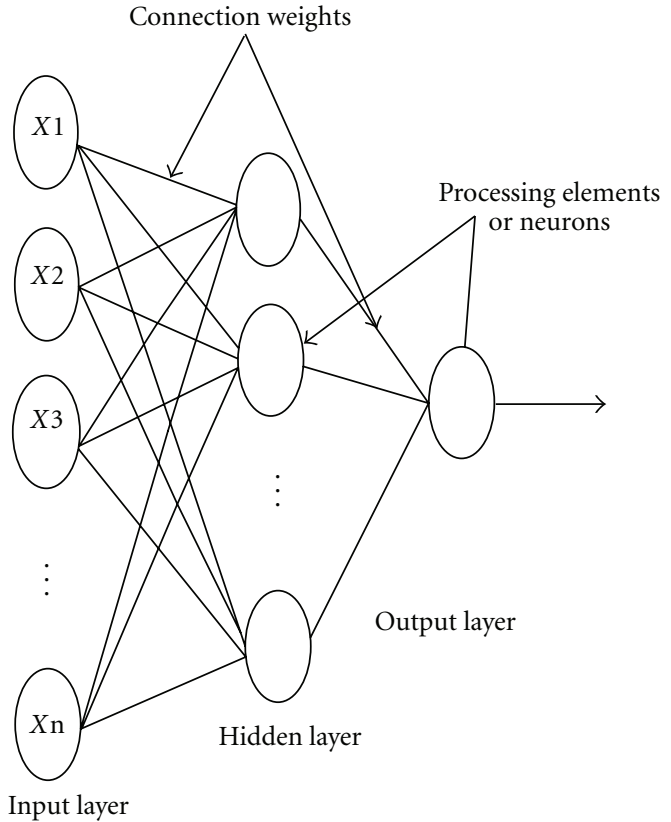

FIGURE 1: The structure of single hidden layer feedforward neural network [18].

neuron's input to determine the output signal. Usually a feed forward neural network consists of several layers of nodes, one input layer, one output layer and some hidden layers in between. The schematic of feed forward neural network with one hidden layer is shown in Figure 1 [18].

The training of a neural network by backpropagation involves three stages: the feedforward of the input training pattern, the calculation and backpropagation of the associated error, and the adjustment of the weights [5]. The calculation of error vector to adjust the weights is done according to the calculated mean square error (MSE) form the difference between actual and predicted outputs according to the following relationships equation:

$$
\text { MSE }=\frac{\sum_{j=0}^{P} \sum_{i=0}^{N}\left(t_{i j}-y_{i j}\right)}{N P},
$$

where $t_{i j}$ and $y_{i j}$ are the target output and predicted output, respectively, for $i$ th training pattern at $j$ th output neuron. $P$ is the total number of output neurons and $N$ indicates the number of training patterns.

In the backward pass, this error signal is propagated backwards to the neural netwrok and the synaptic weights are adjusted in such a manner that the error signal decreases with each iteration process. Thus, the neural network model approaches closer and closer for producing the desired output The corrections necessary in the synaptic weights are carried out by a delta rule, which is expressed by the following equation:

$$
\Delta W_{j i(n)}=-\eta\left\lfloor\frac{\partial(\mathrm{MSE})}{\partial W_{j i(n)}}\right\rfloor,
$$

where $W_{j i(n)}$ is the weight connecting the neurons $j$ and $i$ at the $n$th iteration; $\Delta W_{j i(n)}$ is the correction applied to $W_{j i(n)}$ 


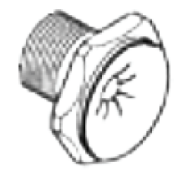

(a)

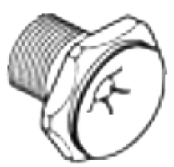

(b)

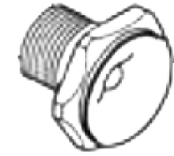

(c)
Figure 2: Different types of navels: (a) 8 flutes, (b) 4 flutes, and (c) without flute.

at the $n$th iteration; $\eta$ is a constant known as learning rate $[7,11]$.

\section{Experimental}

2.1. Materials and Methods. The raw materials used in this investigation were cotton fibers and cotton waste recovered from ginning machines. Cotton fibers were chosen for all mixtures with secondary raw material of three different proportions (50-50\%, 35-65\%, and 65-35\%). Cotton fiber properties were measured by the Spinlab 900 according to ASTM-D4605 [19] Standard Test Method for Measurement of Cotton Fibers by HVI, with a total of four samples taken for evaluation. A summary of raw fiber property has been shown in Table 1.

The blending of fibers was carried out after carding at the first passage in the drawing frame. Second passage was used to improve the homogeneity of blending. Slivers were used to produce yarns with three different linear densities 12, 16, and $20 \mathrm{Ne}$ on Elitex rotor-spinning machine. 81 yarn samples were produced with different machine, yarn and fiber parameters, namely, rotor diameter, rotor speed, opener roller speed, navel type (as shown in Figure 2), ginning waste percentages, and yarn linear density. The setting of the machine for producing these yarns has been shown in Table 2.

Samples were kept in standard testing condition for $24 \mathrm{~h}$ prior to testing. Variations were to be expected within individual yarn bobbins, so the first few meters were discarded. In addition, samples were taken at various locations in the yarn bobbins.

ASTM-D2256 [20] Standard Test Method for Tensile Properties of Yarns by the single-strand method, was used to measure single yarn breaking strength $(\mathrm{cN} /$ tex $)$ by the Instron tensile tester. The testing speed was $60 \mathrm{~mm} / \mathrm{min}$, and the gauge length was $500 \mathrm{~mm}$. Each sample was tested ten times. The irregularity of yarns was measured with reference to ASTM-D 1425 [21], by the Uster Tester 3. A statistical summary of yarn properties produced by different blend ratio has been presented in Table 3 .

2.2. Artificial Neural Network Parameters. For predicting the breaking strength and mass irregularity $\left(\mathrm{CV}_{m} \%\right)$ of cotton/ ginning waste rotor-spun yarns, two feed forward multilayer neural network models based on backpropagation learning algorithm with one neuron as output, and six-input unit in input layer was designed. The input parameters were yarn count $(\mathrm{Ne})$, rotor speed (r.p.m), rotor diameter $(\mathrm{mm})$,
TABLE 1: Fiber properties summary.

\begin{tabular}{lcc}
\hline Fiber characteristics & Cotton & Ginning waste \\
\hline tenacity (cN/tex) & 27.1 & 23.2 \\
Breaking elongation (\%) & 6.7 & 6.6 \\
Mean length by weight (mm) & 23.90 & 21.77 \\
Short fiber content by weight (\%) & 7 & 11.1 \\
Maturity index & 0.82 & 0.81 \\
Micronair & 4.38 & 4.29 \\
UQL (upper quartile length by weight) & 28.89 & 27.19 \\
(mm) & 1.91 & 1.94 \\
CV length by weight (\%) & & \\
\hline
\end{tabular}

TABLE 2: Rotor spinning machine parameters.

\begin{tabular}{ll}
\hline Machine parameters & Description of conditions \\
\hline Rotor diameter (mm) & $48,54,66$ \\
Rotor speed (rpm) & $41000,47000,53000$ \\
Opener roller type & OK40 (for cotton) (fibers) \\
Opener roller speed (r.p.m) & $9800,8400,7350$ \\
Navel type & $($ Steel); 8,4 , and without flutes \\
Delivery speed (m/min) & $52.4 \mathrm{~m} / \mathrm{min}$ \\
\hline
\end{tabular}

opener roller speed (r.p.m), ginning waste percentage, and navel type. All of this parameters were expressed in a vector form. Regarding the qualitative input parameter, namely, navel type, inputs were encoded as 0,1 , and 2.0 referred to navel A, 1 referred to navel $\mathrm{B}$, and 2 indicated navel C.

In this study, due to the availability of only a small sample data, memorization or overfitting of networks was prevented by using the weight decay technique. This involves modifying the performance function. Therefore, mean square error regularization (MSEREG) performance function was used instead of common mean square error function. This function is as follows:

$$
\text { msereg }=\gamma(\mathrm{mse})+(1-\gamma) \mathrm{msw},
$$

where $\gamma$ is the performance ratio and

$$
\mathrm{msw}=\frac{1}{n} \sum_{j=1}^{n} w_{j}^{2}
$$

In (4), $n$ is the number of weighted connection [22].

Samples were divided randomly in training and testing sets. 72 and 9 sets of data were selected for training the neural network models and testing the predictive power of developed models, respectively. To eliminate the effect of different units of input and output parameters, data normalizing was carried out in such a way that they got zero mean and unit standard deviation [23]. The sigmoid and linear transfer functions were used for hidden neurons and output neurons, respectively.

The number of hidden neurons and the number of hidden layers are usually adjusted by trial and error because these are problem-dependent parameters. It is known that 
TABLE 3: Summary of yarn properties produced by different blend ratio.

\begin{tabular}{|c|c|c|c|c|c|c|}
\hline \multirow{2}{*}{ (cotton/ginning waste) } & \multicolumn{3}{|c|}{ Breaking strength (cN/tex) } & \multicolumn{3}{|c|}{ Mass irregularity $\left(\mathrm{CV}_{m} \%\right)$} \\
\hline & Min & Max & Ave & Min & $\operatorname{Max}$ & Ave \\
\hline $65 / 35$ & 7.39 & 11.87 & 9.47 & 14.37 & 19.30 & 16.79 \\
\hline $50 / 50$ & 6.30 & 12.86 & 9.37 & 14.71 & 20.14 & 16.99 \\
\hline $35 / 65$ & 7.01 & 12.44 & 8.77 & 15.68 & 20.38 & 17.70 \\
\hline
\end{tabular}

TABLE 4: Effect of learning rate on performance of ANN model to predict the irregularity and breaking strength (momentum rate was kept constant at 0.7$)$.

\begin{tabular}{lcccc}
\hline Learning rate & \multicolumn{2}{c}{ Breaking strength (cN/tex) } & \multicolumn{2}{c}{ Mass irregularity $\left(\mathrm{CV}_{m} \%\right)$} \\
MSE (train data) & MSE (test data) & 0.830 & MSE (train data) \\
\hline 0.05 & 0.223 & 0.143 & 0.764 & 0.510 \\
0.15 & 0.213 & 0.136 & 0.654 & 0.498 \\
0.30 & 0.245 & 0.113 & 0.538 & 0.429 \\
0.45 & 0.238 & 0.103 & 0.576 & 0.476 \\
0.60 & 0.248 & 0.100 & 0.606 & 0.450 \\
0.75 & 0.262 & 0.095 & 0.757 & 0.475 \\
0.90 & 0.236 & 0.086 & \\
\hline
\end{tabular}

TABLE 5: Performance of different topologies for predicting the mass irregularity and breaking strength of cotton/waste rotor-spun yarns.

\begin{tabular}{lcccc}
\hline Topology & \multicolumn{2}{c}{ Breaking strength (cN/tex) } & \multicolumn{2}{c}{ Mass irregularity } \\
& MSE (test data) & MSE (train data) & MSE (test data) & 0.706 \\
MSE (train data) \\
\hline $6-6-1$ & 0.254 & 0.196 & 0.649 & 0.576 \\
$6-8-1$ & 0.191 & 0.164 & 0.573 & 0.483 \\
$6-10-1$ & 0.238 & 0.153 & 0.596 & 0.446 \\
$6-12-1$ & 0.241 & 0.141 & 0.597 & 0.517 \\
$6-6-6-1$ & 0.251 & 0.164 & 0.567 & 0.476 \\
$6-8-6-1$ & 0.151 & 0.146 & 0.538 & 0.430 \\
$6-8-8-1$ & 0.140 & 0.138 & 0.458 & 0.412 \\
$6-10-8-1$ & 0.188 & 0.123 & 0.660 & 0.377 \\
\hline
\end{tabular}

neural networks with one hidden layer are suitable for majority of applications [24], and the second hidden layer can improve the performance of the network if there is a complex relationship between the input and output parameters. Therefore, 15 topology with one and two hidden layers and six to twelve neurons in hidden layers were tested. The mean square error of testing sets was considered getting the best topology. In Figure 3, the schematic of topologies of ANN models has been illustrated.

\section{Results and Discussion}

3.1. Artificial Neural Network Models. To identify the optimum value of learning and momentum rate, some trials with 6-8-6-1 topology in the 2000 epoch was organized. The obtained results showed that the suitable level of learning rate is 0.15 and 0.45 for models of breaking strength and mass irregularity $\left(\mathrm{CV}_{m} \%\right)$, respectively, (Table 4$)$. Then the optimized value of learning rate was used to optimize the momentum rate. As shown in Figures 4 and 5, the momentum rate was changed from 0.1 to 0.9 with 0.2 step. It is clear from Figures 4 and 5 that the 0.9 and 0.7 are the optimum values of momentum rate for two models, respectively. In these values, the best performance of models for predicting the testing data was obtained. The influence of momentum rate on training performance of ANN models was small.

A summary of training results for 9 topologies out of 15 selected topologies have been presented in Table 5. In these steps, the optimized values of learning rate and momentum rate were applied in training process for both models. The results showed that the ANN model with two hidden layers and 8 processing elements into first and second hidden layers gives the best performance and the least MSE on testing data for predicting the breaking strength of cotton/ginning watses rotor-spun yarns after the 2000 epoch. On the other hand, the 6-10-8-1 topology, that is, 10 and 8 neurons in first and 


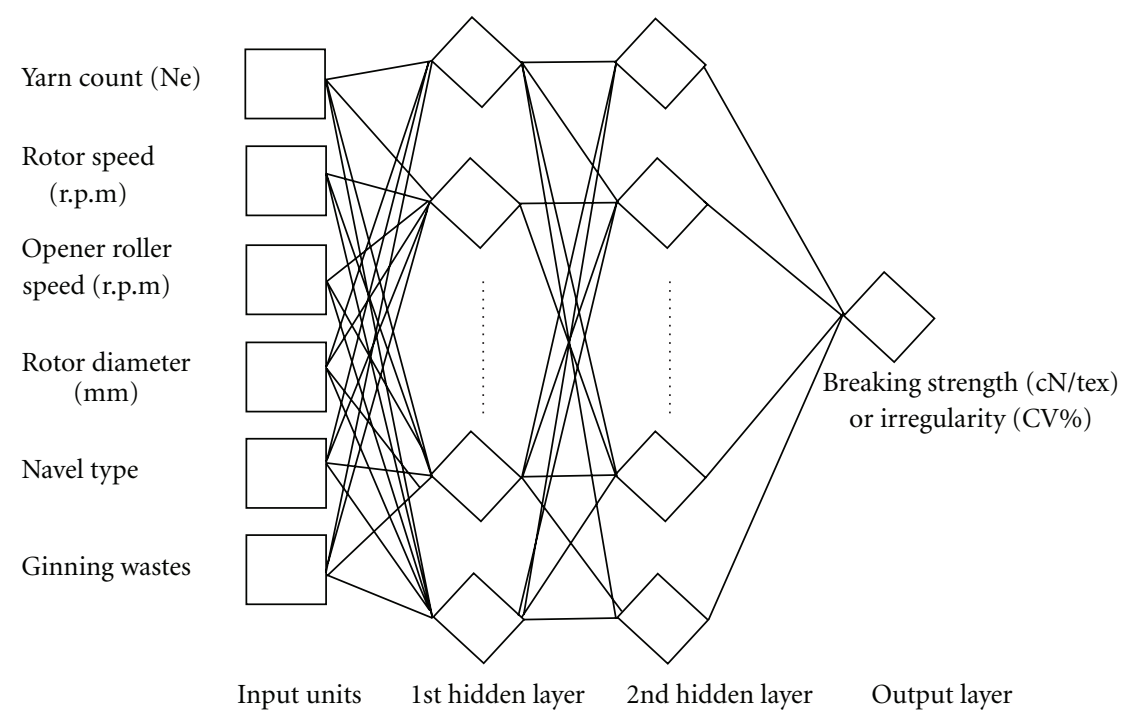

FIGURE 3: Schematic of ANN model to predict the breaking strength and irregularity of cotton/cotton ginning watse rotor-spun yarns.

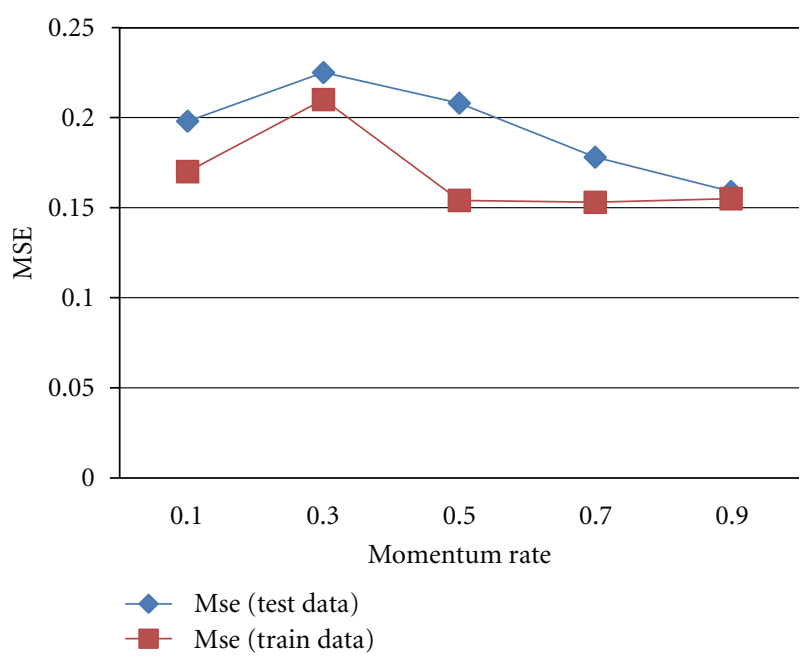

FIGURE 4: Effect of momentum rate on performance of ANN model to predict the breaking strength (learning rate was kept constant at $0.15)$.

second hidden layer, respectively, gave the best performance for predicting the mass irregularity $\left(\mathrm{CV}_{m} \%\right)$. In Figures 6 and 7 , training performance of two models based on linear regression fitted between the target value, and predicted value of training data have been shown. The $R$-value of breaking strength model was 0.931 , and irregularity model $\left(\mathrm{CV}_{m} \%\right)$ was 0.948 .

In the obtained model for prediction, the breaking strength, the mean square error of testing and training data was 0.140 and 0.138 , respectively. The experimental data to verify the predictive power of proposed models have been shown in Table 6. In Table 7, the predicted values and prediction error for breaking strength of cotton/ginning waste rotor-spun yarns have been presented. It is clear that the predictive power of proposed method is satisfactory and

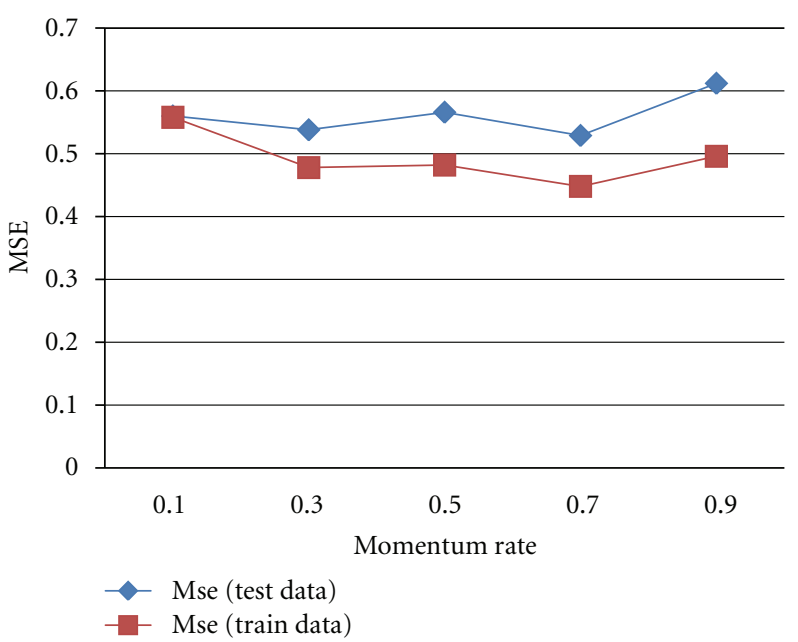

FIGURE 5: Effect of momentum rate on performance of ANN model to predict the mass irregularity (learning rate was kept constant at $0.45)$.

the minimum error on testing data is $0.09 \%$ and the maximum error is $8.34 \%$. The average of prediction error is $3.1 \%$.

The mean square error of testing and training data on predictive model of mass irregularity was 0.412 and 0.318 , respectively. It is observed from Table 8 that the minimum and maximum of prediction error was $0.37 \%$ and $6.65 \%$, respectively. The mean error rate of prediction of irregularity were $3.08 \%$. All outcomes clearly approved the good capability of ANN model to predict the mass irregularity of cotton/ginning waste rotor-spun yarns.

\subsection{Analysis of the Impact of Rotor-Spun Yarn Production} Parameters. According to method used by Majumdar et al. [11], the relative contribution of each inputs to the breaking strength and mass irregularity $\left(\mathrm{CV}_{m} \%\right)$ of cotton/ginning 
TABLE 6: The parameters of testing data of ANN models.

Parameter

Sample no. Ginning waste (\%) Yarn count (Ne) Rotor diameter (mm) Opener roller speed (r.p.m) Rotor speed (r.p.m) Navel type

\begin{tabular}{|c|c|c|c|c|c|c|}
\hline 1 & 65 & 12 & 66 & 8400 & 48000 & B \\
\hline 2 & 50 & 16 & 66 & 9700 & 53000 & C \\
\hline 3 & 35 & 12 & 54 & 9700 & 41000 & A \\
\hline 4 & 35 & 20 & 54 & 8400 & 53000 & B \\
\hline 5 & 35 & 20 & 66 & 7350 & 41000 & C \\
\hline 6 & 65 & 12 & 54 & 9700 & 41000 & A \\
\hline 7 & 50 & 12 & 54 & 9700 & 41000 & C \\
\hline 8 & 35 & 12 & 54 & 9700 & 41000 & B \\
\hline 9 & 65 & 12 & 66 & 8400 & 48000 & A \\
\hline
\end{tabular}

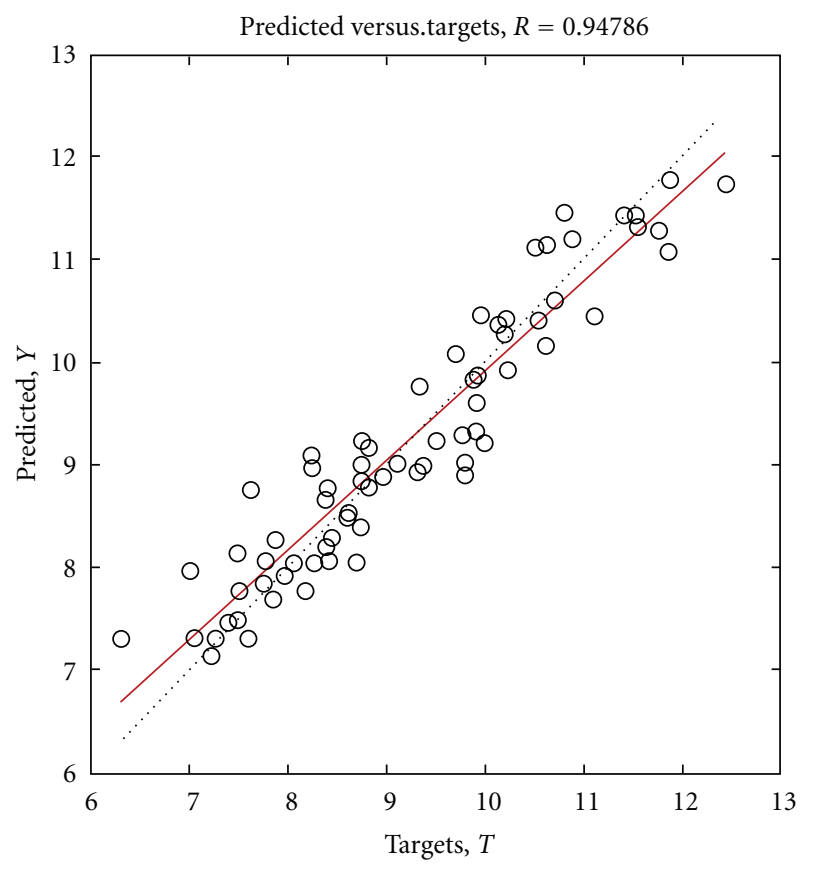

O Data points

Best linear fit

$$
\cdots \cdots=T
$$

FIGURE 6: Training performance of ANN model for prediction of mass irregularity.

waste rotor-spun yarns has been studied. An input significant test was conducted by eliminating one designated input from the model at a time. Based on the obtained parameters, the network was trained again and the prediction was made from the testing data. The percent increase in the mean squared error of prediction as compared to that of optimized neural network models was considered as the indicator of importance of the eliminated input. Effectiveness of process parameters on breaking strength and mass irregularity has been shown in Tables 9 and 10, respectively.

It is clear form Table 9 that the rotor speed and waste percentage showed the major effect on breaking strength of cot-

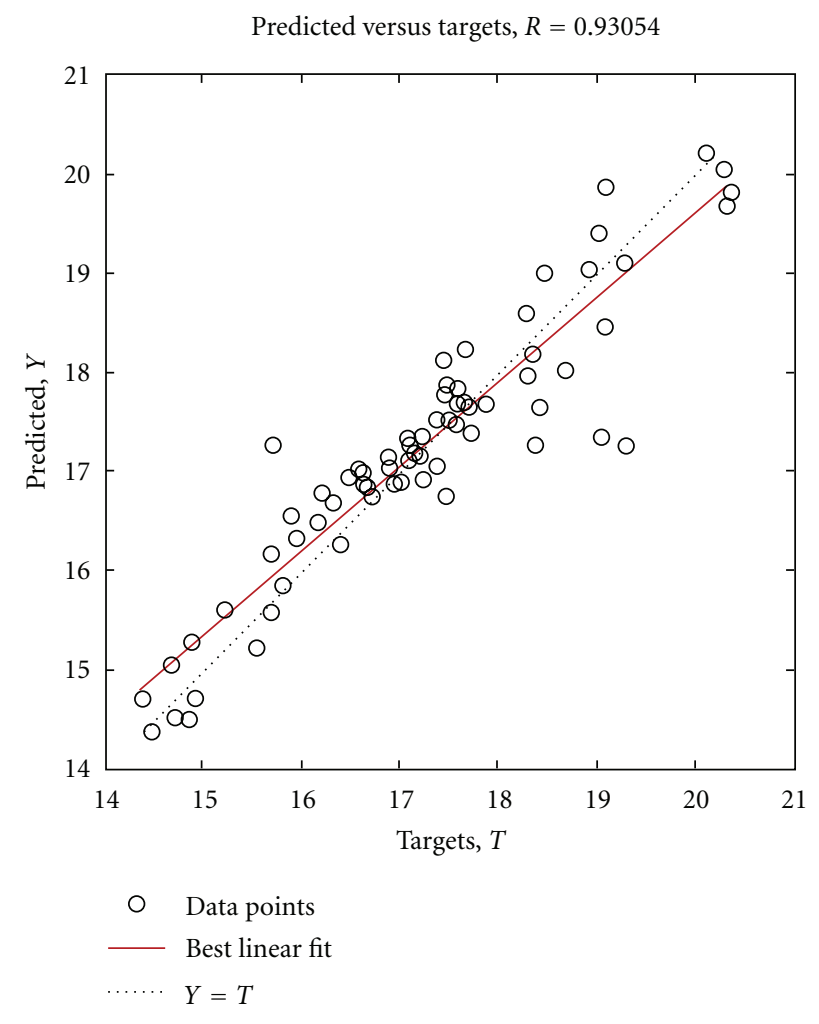

FIGURE 7: Training performance of ANN models for prediction of breaking strength.

ton/ginning waste rotor-spun yarns. The findings confirmed by many researchers [25-27] refer to significant effect of rotor speed on the yarn breaking strength. On the other hand and according to Table 1, the waste percentage determines the amount of short fiber contributed in yarn structure and average length of fiber which significantly affects the yarn breaking strength.

Regarding the mass irregularity (as shown in Table 10), the ginning waste percentage and yarn count were the most important parameters on mass irregularity $\left(\mathrm{CV}_{m} \%\right)$. As shown in Table 3, by increasing the ginning waste percentage in rotor-spun yarn structure, the increase of yarn irregularity 
TABLE 7: The Breaking strength (cN/tex) values predicted by the ANN model with 6-8-8-1 topology on testing data.

\begin{tabular}{lcccc}
\hline Sample no. & $\begin{array}{c}\text { Experimental } \\
\text { value }\end{array}$ & $\begin{array}{c}\text { Predicted } \\
\text { value }\end{array}$ & Abs. error & $\begin{array}{c}\text { Error rate } \\
(\%)\end{array}$ \\
\hline 1 & 9.53 & 9.74 & 0.21 & 2.22 \\
2 & 10.98 & 10.97 & -0.01 & 0.09 \\
3 & 9.68 & 10.48 & 0.81 & 8.34 \\
4 & 8.94 & 9.04 & 0.09 & 1.07 \\
5 & 7.39 & 7.59 & 0.19 & 2.69 \\
6 & 9.68 & 9.21 & -0.48 & 4.95 \\
7 & 9.95 & 9.53 & -0.42 & 4.23 \\
8 & 9.09 & 9.19 & -0.09 & 1.04 \\
9 & 9.90 & 10.23 & -0.33 & 3.32 \\
\hline
\end{tabular}

TABLE 8: The mass irregularity $\left(\mathrm{CV}_{m} \%\right)$ values predicted by the ANN model with 6-10-8-1 topology on testing data.

\begin{tabular}{lcccc}
\hline Sample no. & $\begin{array}{c}\text { Experimantal } \\
\text { value }\end{array}$ & $\begin{array}{c}\text { Predicted } \\
\text { value }\end{array}$ & Abs. error & $\begin{array}{c}\text { Error rate } \\
(\%)\end{array}$ \\
\hline 1 & 16.08 & 16.26 & -0.18 & 1.13 \\
2 & 15.22 & 14.25 & 0.96 & 6.32 \\
3 & 18.15 & 19.35 & -1.20 & 6.64 \\
4 & 16.59 & 16.22 & 0.36 & 2.17 \\
5 & 16.29 & 15.75 & 0.53 & 3.26 \\
6 & 19.07 & 20.18 & -1.11 & 5.84 \\
7 & 16.53 & 16.59 & -0.06 & 0.37 \\
8 & 16.29 & 16.14 & 0.14 & 0.89 \\
9 & 15.68 & 15.52 & 0.15 & 1.01 \\
\hline
\end{tabular}

is observed. This could be the reason to observe this parameter as the most effective one on mass irregularity of cotton/ ginning waste rotor-spun yarns. Opener roller speed had the least impact on breaking strength and irregularity.

\section{Conclusion}

The presented work demonstrated the application of artificial neural network algorithm for predicting the breaking strength and mass irregularity of cotton/ginning waste rotorspun yarns based on rotor diameter, rotor speed, navel type, opener roller speed, ginning waste proportion, and yarn linear density. Our findings indicated the good capability of artificial neural network algorithm as predictive model. These proposed models obviously will reduce the required time to produce the cotton/ginning waste in accordance to specific properties in spinning mills. The results showed that the artificial neural network model with two hidden layers and 8 processing elements into the first and second hidden layers gives the best performance and the least MSE on testing data for predicting the breaking strength of cotton/ginning watses rotor-spun yarns. On the other hand, the 6-10-8-1 topology, that is, 10 and 8 neurons in first and second hidden layer, respectively, gave the best performance for predicting the mass irregularity $\left(\mathrm{CV}_{m} \%\right)$. The mean square error to predict testing data was 0.140 and 0.4120 for breaking
TABLE 9: Effectiveness of input parameters on breaking strength.

\begin{tabular}{lccc}
\hline Excluded input parameter & MSE & $\begin{array}{c}\text { Increase in mean } \\
\text { square error }(\%)\end{array}$ & Ranking \\
\hline Rotor speed & 0.442 & 216.285 & 1 \\
Rotor diameter & 0.289 & 106.714 & 3 \\
Opener roller speed & 0.153 & 9.928 & 6 \\
Navel type & 0.254 & 81.926 & 4 \\
Waste percentage & 0.428 & 206.214 & 2 \\
Yarn count & 0.249 & 78.285 & 5 \\
\hline
\end{tabular}

TABLE 10: Effectiveness of input parameters on mass irregularity.

\begin{tabular}{lccc}
\hline Excluded input parameter & MSE & $\begin{array}{c}\text { Increase in mean } \\
\text { square error (\%) }\end{array}$ & Ranking \\
\hline Rotor speed & 0.588 & 28.524 & 5 \\
Rotor diameter & 0.695 & 51.855 & 4 \\
Opener roller speed & 0.546 & 19.227 & 6 \\
Navel type & 0.803 & 75.316 & 3 \\
Waste percentage & 0.901 & 96.704 & 1 \\
Yarn count & 0.883 & 92.885 & 2 \\
\hline
\end{tabular}

strength and mass irregularity of cotton/ginning waste, respectively. The effectiveness of input parameters was also evaluated. Waste percentage and yarn count were found major parameters on mass irregularity of rotor-spun yarn and rotor speed and waste percentage were also found as the most effective parameters on breaking strength of rotor-spun yarn. Moreover, opening roller speed showed the least effectiveness on both mentioned parameters. In recent studies, developing predictive models based on artificial neural network algorithm for prediction of the hairiness and breaking elongation and also optimization of input parameters using genetic algorithm have been focused.

\section{References}

[1] T. M. Halimi, B. M. Hassen, B. Azzouz, and F. Sakli, "Effect of cotton waste and spinning parameters on rotor yarn quality," Journal of the Textile Institute, vol. 98, no. 5, pp. 437-442, 2007.

[2] H. Deussen, Rotor Spinning Technology, Schlafhorst, Charlotte, NC, USA, 1993.

[3] I. Hanafy, "Fabric from cotton waste," The Indian Textile Journal, pp. 16-18, 1997.

[4] H. M. Taher, A. Bechir, B. H. Mohamed, and S. Faouzi, "Influence of spinning parameters and recovered fibers from cotton waste on the uniformity and hairiness of rotor spun yarn," Journal of Engineered Fibers and Fabrics, vol. 4, no. 3, pp. 36-44, 2009.

[5] L. Fausett, Fundamentals of Neural Networks, Prentice Hall, Upper Saddle River, NJ, USA, 1994.

[6] R. Rajamanickam, S. Hansen, and S. Jayaraman, "Analysis of the modeling methodologies for predicting the strength of airjet spun yarns," Textile Research Journal, vol. 67, no. 1, pp. 3944, 1997.

[7] R. Beltran, L. Wang, and X. Wang, "Predicting worsted spinning performance with an artificial neural network model," Textile Research Journal, vol. 74, no. 9, pp. 757-763, 2004. 
[8] Y. C. Zeng, K. F. Wang, and C. W. Yu, "Predicting the tensile properties of air-jet spun yarns," Textile Research Journal, vol. 74, no. 8, pp. 689-694, 2004.

[9] P. K. Majumdar and A. Majumdar, "Predicting the breaking elongation of ring spun cotton yarns using mathematical, statistical, and artificial neural network models," Textile Research Journal, vol. 74, no. 7, pp. 652-655, 2004.

[10] M. C. Ramesh, R. Rajamanickam, and S. Jayaraman, "The prediction of yarn tensile properties by using artificial neural networks," Journal of the Textile Institute, vol. 86, no. 3, pp. 459-469, 1995.

[11] A. Majumdar, P. K. Majumdar, and B. Sarkar, "Application of linear regression, artificial neural network and neuro-fuzzy algorithms to predict the breaking elongation of rotor-spun yarns," Indian Journal of Fibre and Textile Research, vol. 30, no. 1, pp. 19-25, 2005.

[12] L. Cheng and D. L. Adams, "Yarn strength prediction using neural networks part I: fiber properties and yarn strength relationship," Textile Research Journal, vol. 65, no. 9, pp. 495$500,1995$.

[13] R. Zhu and M. D. Ethridge, "Predicting hairiness for ring and rotor spun yarns and analyzing the impact of fiber properties," Textile Research Journal, vol. 67, no. 9, pp. 694-698, 1997.

[14] S. Sette, L. Boullart, L. Van Langenhove, and P. Kiekens, "Optimizing the fiber-to-yarn production process with a combined neural network/genetic algorithm approach," Textile Research Journal, vol. 67, no. 2, pp. 84-92, 1997.

[15] O. Demiryürek and E. Koç, "The mechanism and/or prediction of the breaking elongation of polyester/viscose blended open-end rotor spun yarns," Fibers and Polymers, vol. 10, no. 5, pp. 694-702, 2009.

[16] A. A. Gharehaghaji, M. Shanbeh, and M. Palhang, "Analysis of two modeling methodologies for predicting the tensile properties of cotton-covered nylon core yarns," Textile Research Journal, vol. 77, no. 8, pp. 565-571, 2007.

[17] J. C. Principe, N. R. Euliano, and W. C. Lefebvre, Neural and Adaptive Systems, John Wiley and Sons, New York, NY, USA, 1999.

[18] H. Hasani and M. Shanbeh, "Application of multiple linear regression and artificial neural network algorithms to predict the total handle value of summer knitted T-shirts," Indain Journal of Fiber and Textile Research, vol. 35, pp. 222-227, 2010.

[19] “IS: ASTM-D4605,” ASTM Standards Specifications, ASTM International, West Conshohocken, Pa, USA, 1998.

[20] “IS: ASTM-D2256," ASTM Standards Specifications, ASTM International, West Conshohocken, Pa, USA, 1998.

[21] “IS: ASTM-D1425," ASTM Standards Specifications, ASTM International, West Conshohocken, Pa, USA, 1998.

[22] H. Demuth and M. Beale, Neural Network Toolbox/Matlab Software, The mathworks Inc, Natick, Mass, USA, 2001.

[23] S. Debnath, M. Madhusoothanan, and V. R. Srinivasmoorthy, "Modelling of tensile properties of needle-punched nonwovens using artificial neural networks," Indian Journal of Fibre and Textile Research, vol. 25, no. 1, pp. 31-36, 2000.

[24] R. Chattopadhyay, "Application of neural network in yarn manufacture," Indian Journal of Fibre and Textile Research, vol. 31, no. 1, pp. 160-169, 2006.

[25] J. Derichs, "Theoretical and practical limits of rotor spinning in the production of fine yarns," Schlafhorst Documentation, no. 16, p. a141, 1986.

[26] W. Kampen, J. Lunenschloss, and T. T. Phoa, "Influencing the structure of OE-rotor yarns-possibilities and limits," International Textile Buletin, vol. 79, no. 3, pp. 373-498, 1979.
[27] C. A. Lawrence and K. Z. Chen, "Rotor spinning," in Textile Progress, vol. 13, no. 4, pp. 17-19, Textile Institute, Manchester, UK, 1984. 

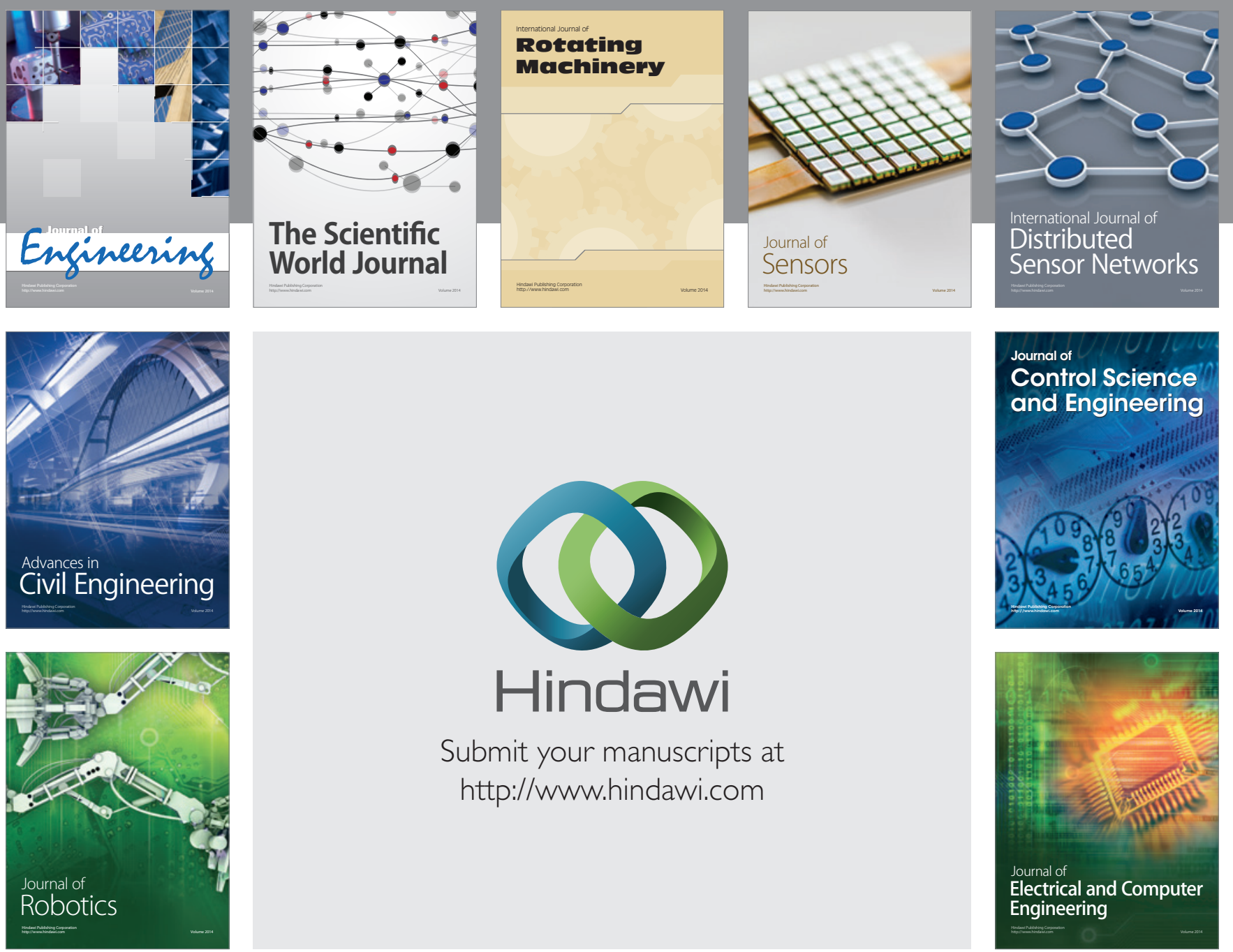

Submit your manuscripts at

http://www.hindawi.com
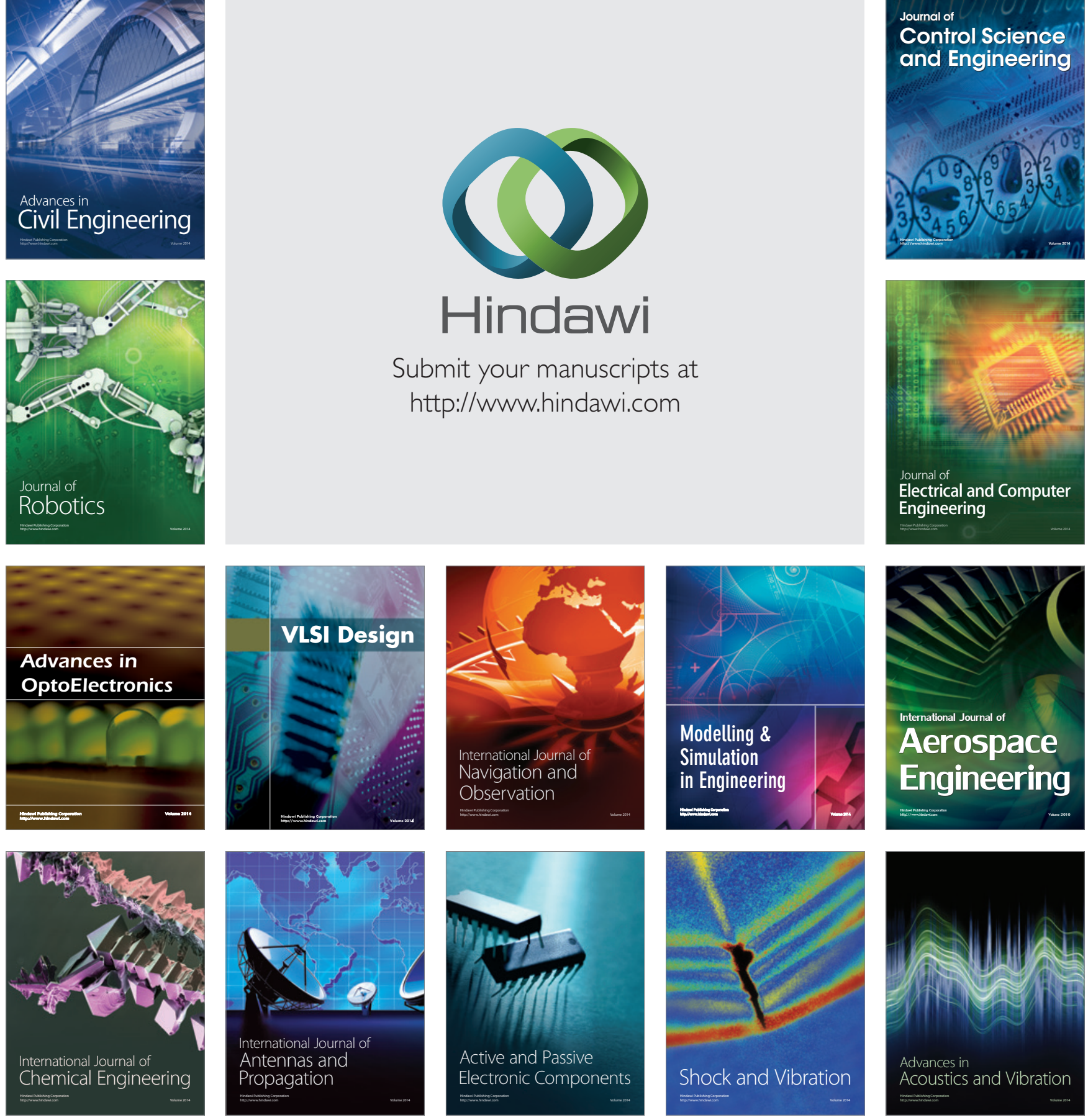